Revista de Iniciação Científica em Odontologia. 2018;16(3):109-117

ISSN 1677-3527 - DOI: 10.4034/RevIC0.2018.16.3.11

Relato de Caso

\title{
Enucleação de Cisto Dentígero Associado a Terceiro Molar Inferior: Relato de caso
}

\section{Enucleation of Dentigerous Cyst Associated with Third Lower Molar: Case Report}

Júlia Quintela Brandão de Gusmão; Lucas Emmanuell de Morais Neves'; Sirius Dan Inaoka2;

Davi Felipe Neves da Costa3; Murilo Quintão dos Santos4; Tiburtino José de Lima Neto ${ }^{4}$

${ }^{1}$ Graduando(a) em odontologia, Universidade Estadual da Paraíba, Araruna, Brasil;

2 Cirurgião Bucomaxilofacial do Hospital Universitário Lauro Wanderley, João Pessoa, Brasil; 3Mestre em Odontologia pela Universidade Federal da Paraíba e Cirurgião Bucomaxilofacial do Hospital Universitário Lauro Wanderley (HULW), João Pessoa, Brasil;

${ }^{4}$ Residente de Cirurgia e Traumatologia Bucomaxilofacial da Universidade Federal da Paraíba (UFPB), João Pessoa, Brasil.

Autor e endereço para correspondência:

Tiburtino José de Lima Neto, Avenida Epitácio Pessoa, 4595, Tambaú, CEP: 58.039-000, E-mail:

TiburtinoNeto@hotmail.com

\begin{abstract}
Resumo
Introdução: O Cisto Dentígero é uma neoplasia benigna intraóssea, revestida por uma cápsula de tecido epitelial odontogênico, caracterizada pelo envolvimento com a coroa de um dente incluso, principalmente terceiros molares. O procedimento cirúrgico, do tipo enucleação cística, é indicado devido à possibilidade de fraturas patológicas e deformidades ósseas. Objetivo: Descrever a conduta de enucleação cirúrgica realizada em um cisto dentígero em mandíbula associado a um terceiro molar incluso. Relato de caso: Paciente do sexo feminino, 28 anos, encaminhada pelo ortodontista para avaliação cirúrgica, após realização de exame de imagem panorâmico de rotina, onde se evidenciou uma lesão radiolúcida associada à coroa do dente 38 incluso. Clinicamente, não apresentava sinais de infecção e não houve relato de sintomatologia. Devido ao tamanho da lesão, foi realizada com fins de diagnóstico e terapêutico a biópsia excisional associada à exodontia do dente incluso, em seguida, foi realizada a osteotomia periférica, objetivando a remoção de possíveis células satélites. O resultado do exame histopatológico revelou um Cisto Dentígero. Após três meses de acompanhamento, observou-se neoformação óssea e cicatrização tecidual adequada. Conclusão: As lesões císticas são achados comuns na prática clínica. Tendo em vista que tais lesões podem alcançar grandes proporções, resultando em assimetria facial, reforça a indicação de remoção cirúrgica. Para este caso, a enucleação do cisto em conjunto com a exodontia do dente incluso demonstrou-se uma abordagem terapêutica viável para o tratamento dessa patologia.
\end{abstract}

Descritores: Cisto Dentígero. Cistos Odontogênicos. Dente não Erupcionado. 


\begin{abstract}
Introduction: Dentigero cyst is a benign intraosseous neoplasia, covered by a capsule of odontogenic epithelial tissue, characterized by involvement with the crown of an included tooth, mainly third molars. The surgical procedure, such as cystic enucleation, is indicated due to the possibility of pathological fractures and bone deformities. Objective: To describe the conduct of surgical enucleation performed in a mandibular dentigerous cyst associated with an even third molar. Case report: Female patient, 28 years old, referred by the orthodontist for surgical evaluation, after a routine panoramic image examination, where a radiolucent lesion associated with the crown of the tooth 38 was evidenced. Clinically, there were no signs of infection and no symptomatology was reported. Due to the size of the lesion, the excisional biopsy associated to the exodontia of the included tooth was performed for diagnostic and therapeutic purposes, after which a peripheral osteotomy was performed, aiming at the removal of possible satellite cells. The result of the histopathological examination revealed a Dentigerous Cyst. After three months of follow-up, bone neoformation and adequate tissue healing were observed. Conclusion: Cystic lesions are common findings in clinical practice. Considering that such lesions can reach large proportions, resulting in facial asymmetry, it reinforces the indication of surgical removal. In this case, the enucleation of the cyst together with the tooth extraction even demonstrated a viable therapeutic approach for the treatment of this pathology.
\end{abstract}

Keywords: Dentigerous cyst; Odontogenic Cysts; Unruptured tooth.

\title{
Introdução
}

Os dentes inclusos têm sido abordados na literatura como os elementos que após o período normal de erupção não conseguiram se posicionar na arcada, estando parcialmente ou inteiramente recoberto por tecido ósseo. Essa condição apresenta etiologia multifatorial, como por exemplo, barreiras mecânicas: cistos, tumores, dentes supranumerários e estruturas ósseas mais densas $^{1,2,3}$. Os terceiros molares são os dentes mais acometidos por tal situação, seguidos pelos supranumerários, caninos superiores e os pré-molares, sendo então passiveis de identificação através de exames de imagem de rotina ${ }^{2,3,4}$.

As indicações para extração de terceiros molares inclusos abrangem pericoronarite recorrente, comprometimento de estruturas adjacentes, acometimento de cistos e tumores ${ }^{5}$. No entanto, ainda que pesquisas recentes tenham descritos os benefícios da extração preventiva de dentes inclusos, esse procedimento pode ocasionar complicações severas, tais como danos aos nervos e infecções ${ }^{5}$.

Entre os cistos odontogênicos não inflamatórios, o cisto dentígero é considerado o mais incidente, sendo esse associado à coroa de um dente incluso, localizados normalmente na região 
da raiz distal do terceiro molar mandibular, com maior prevalência em pacientes masculinos, de origem caucasiana e na segunda ou terceira décadas de vida ${ }^{4-10}$. Apesar da etiopatogenia dessa condição ser por muitos, descrito como incerta, acredita-se que a patogênese de tal lesão ocorra devido ao acúmulo de fluidos entre a coroa e o epitélio reduzido do esmalte, podendo ser consequência da pressão exercida por um folículo dentário no processo eruptivo ${ }^{6-8,10}$.

Clinicamente, o cisto dentígero apresenta-se de forma assintomática podendo, no entanto, apresentar sintomatologia quando associada a processos inflamatórios, bem como ocasionar expansão lenta da cortical óssea e consequentemente assimetria facial ${ }^{6,8,10,11}$. Através dos exames de imagens, observa-se uma imagem radiotransparente, unilocular de limites bem definidos e com margens escleróticas fina, em torno da coroa de um dente incluso ${ }^{8-10}$.

O tratamento de escolha para esta lesão, normalmente, é cirúrgico, sendo a marsupialização ou a enucleação associada à extração do elemento dentário. Como fatores a serem avaliados para tal escolha têm-se: a idade do paciente, localização do cisto e a posição do dente em relação ao cisto e outras estruturas anatômicas ${ }^{2,6,8,9}$.

Diante disso, o propósito do presente artigo é descrever a conduta de enucleação cirúrgica realizada em um cisto dentígero em mandíbula, associado a um terceiro molar incluso.

\section{Relato de caso}

Paciente do sexo feminino, 28 anos, encaminhada por um cirurgião-dentista para avaliação cirúrgica, após ter realizado exames de rotina pra início do tratamento ortodôntico, apresentou, em um dos exames realizados (radiografia panorâmica), lesão radiolúcida de aproximadamente $2,0 \times 1,8 \times 0,7 \mathrm{~cm}$, bem delimitada por halo fino radiopaco, envolvendo a coroa do dente 38. O dente estava incluso com angulação horizontal, segundo classificação de Winter, e com suspeita de contato com o canal alveolar inferior, segundo a classificação de Rood e Shehab (1990), devido ao escurecimento na região da raiz (Figura. 1). Por tais motivos, o diagnóstico clínico foi de Cisto Dentígero. 


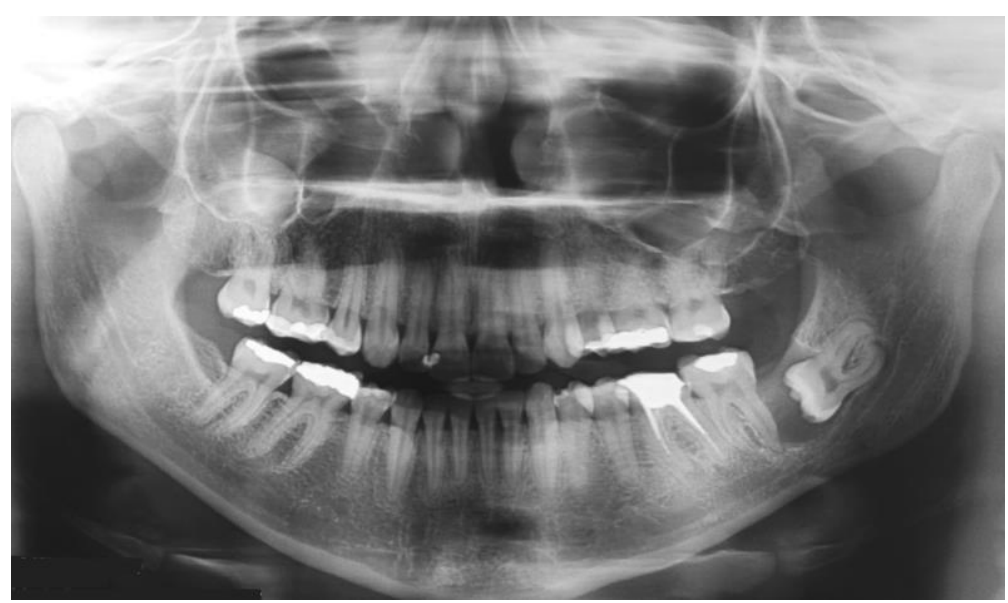

Figura 1: Exame de imagem do tipo panorâmica, pré-cirurgica, evidenciando lesão cística envolvendo o terceiro molar inferior esquerdo (38) de angulação horizontal, compatível com Cisto

\section{Dentígero}

Clinicamente não foi relatada sintomatologia dolorosa, nem observado sinais de infecção e aumento de volume extra (Figura. 2) e intra oral (Figura. 3). Devido às características clínicas e ao tamanho observado através do exame de imagem, foi planejada a biópsia excisional e exodontia do dente envolvido.

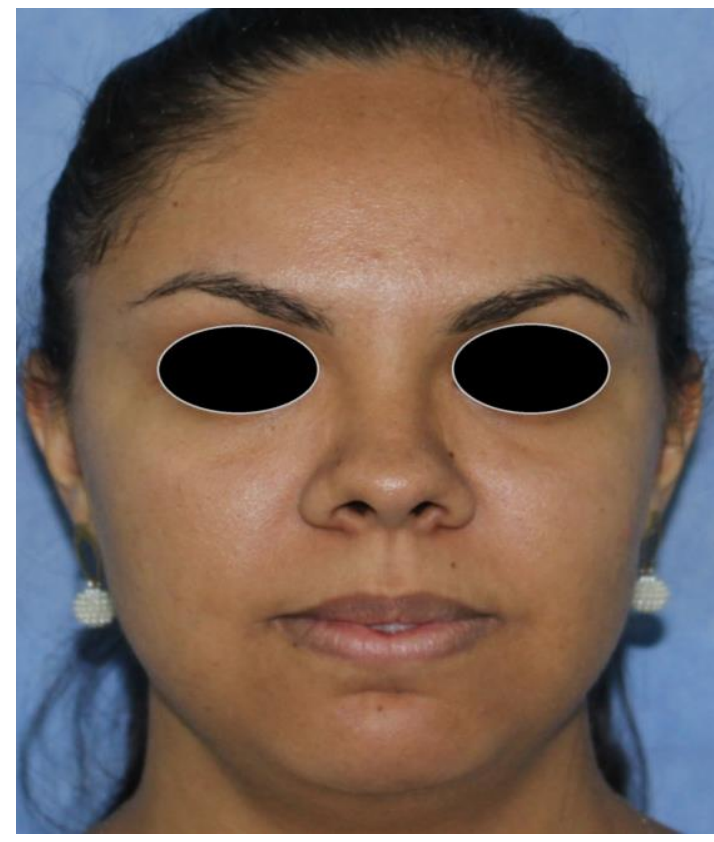

Figura 2: Fotografia extraoral evidenciando ausência de assimetria facial. 


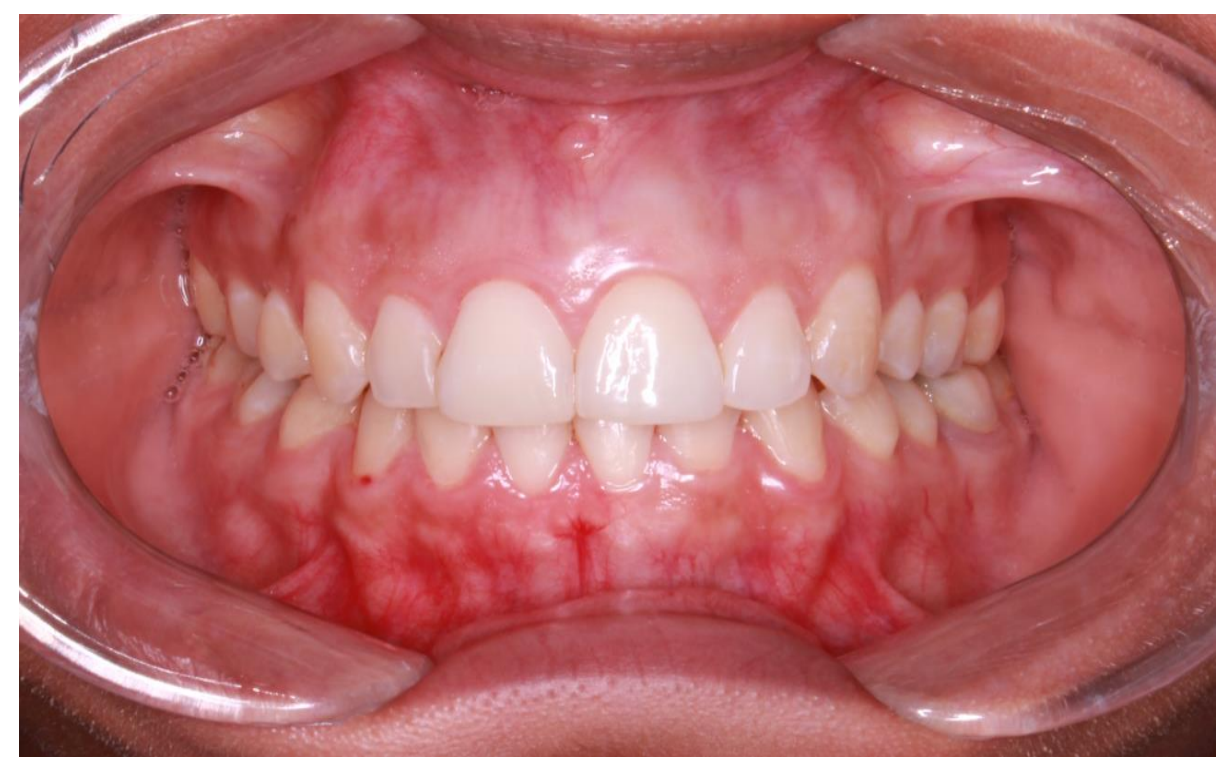

Figura 3: Fotografia intra-oral evidenciando ausência de tumefações e abaulamento na cortical óssea.

A paciente foi submetida à cirurgia em ambiente ambulatorial, sob anestesia local do tipo Articaína a 4\% com adrenalina (Articaine), através do bloqueio dos nervos lingual, bucal e alveolar inferior. O acesso foi feito pela incisão de Newman e foram expostos o elemento dentário e a lesão (Figura. 4), sendo realizado a enucleação cística (Figura. 5A) e a exodontia do dente 38 associado à lesão (Figura. 5B). A fim de diminuir a resistência na remoção do dente, bem como, manter a preservação da tábua óssea, optou-se por realizar a odontosecção, dividindo as raízes e removendo-as individualmente (Figura. 5B).

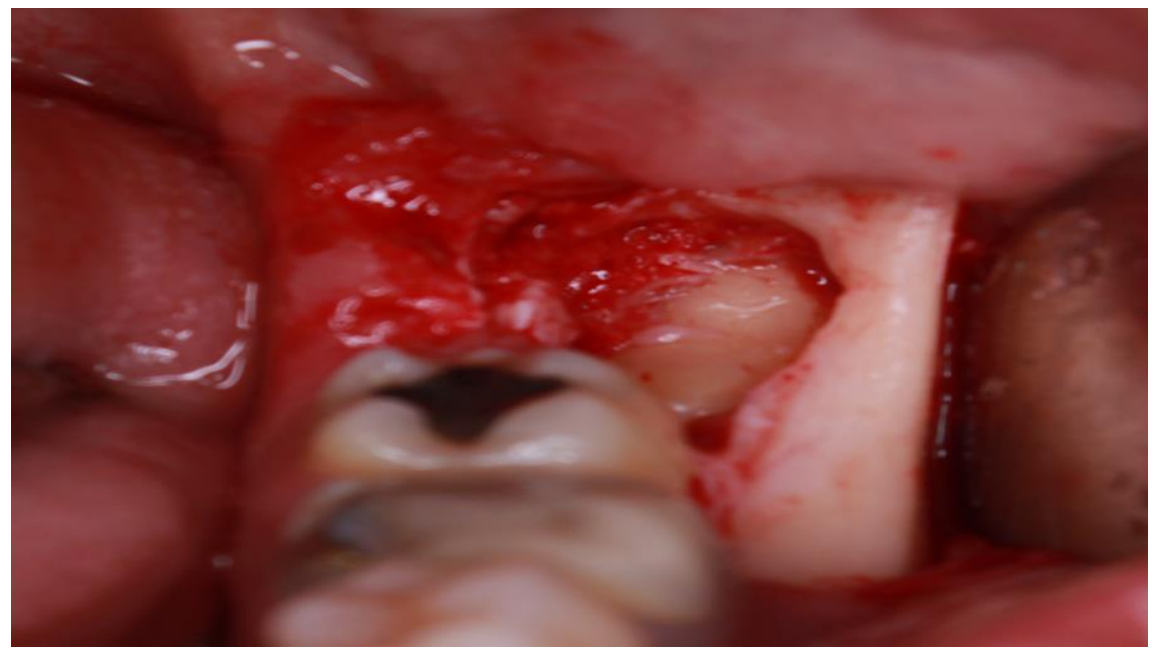

Figura 4: Exposição da lesão, em campo cirúrgico, através da abertura de retalho e osteotomia. 


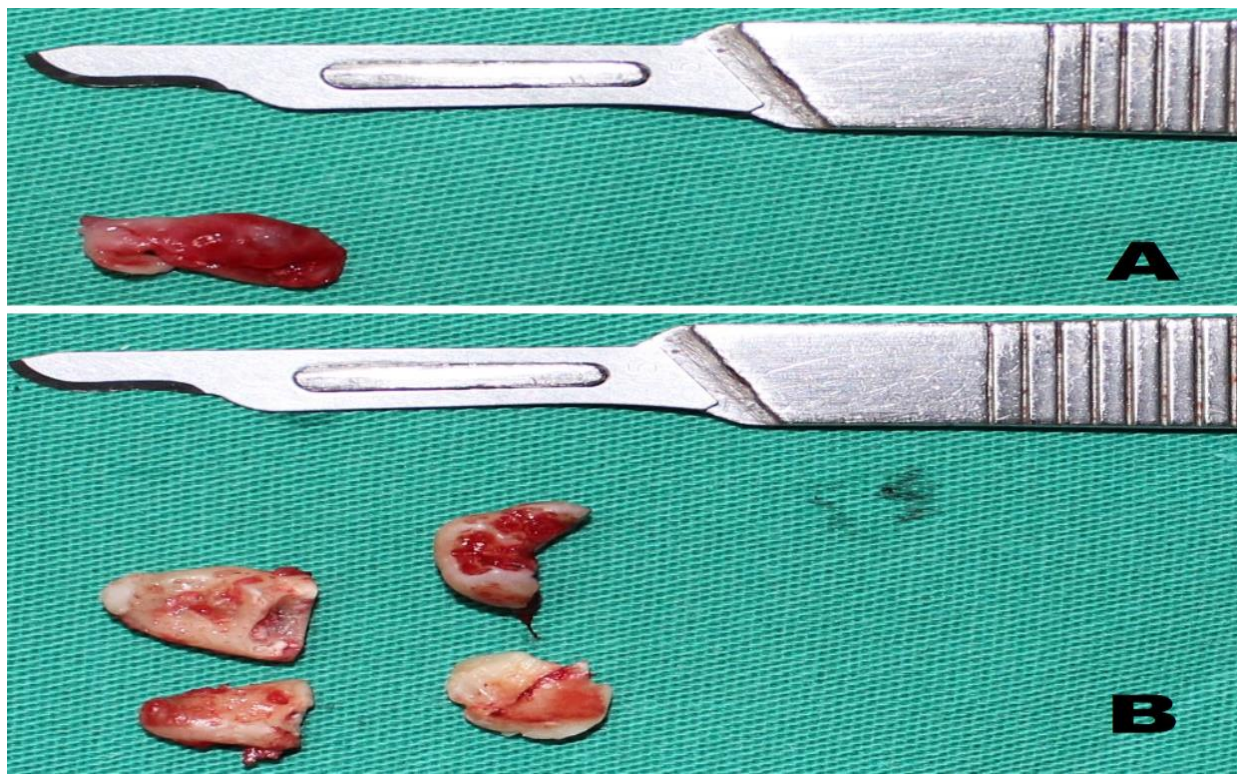

Figura 5: (A) Lesão cística de aproximadamente $3,0 \mathrm{~cm}$. (B) Exodontia do dente

38, realizada sob a técnica de odontosecção.

Após a exodontia e biópsia excisional, foi realizada a osteotomia periférica para garantir a remoção de possíveis células satélites. O diagnóstico, após o resultado do exame histopatológico, revelou um cisto dentígero. No controle pós-operatório de 3 meses, a paciente evoluía bem, sem sinal de recidiva da lesão cística após o procedimento cirúrgico e sem déficits sensoriais de qualquer nervo, bem como foi possível observar através da panorâmica pós-operatória a neoformação óssea (Figura. 6) e cicatrização adequada dos tecidos em região cirúrgica.

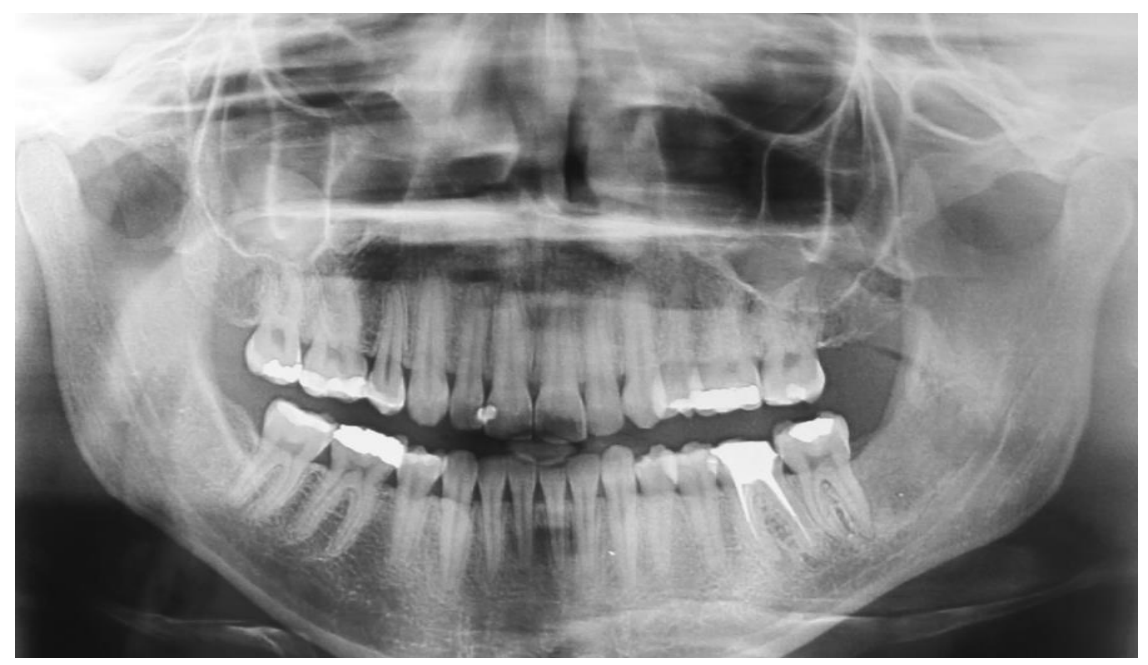

Figura 6: Radiografia Panorâmica, após 3 meses do procedimento cirúrgico, evidenciando neoformação óssea adequada em região pós-cirurgica. 


\section{Discussão}

Estudos apontam que a maior prevalência de impactação, entre todos os dentes, pertence aos terceiros molares superiores (com média de 26\%), seguidos pelos terceiros molares inferiores (com média de 19,25\%), supranumerários (em torno de $5 \%$ ) e os caninos superiores $(1,30 \%)^{1}$. Especificamente, o elemento dentário 38, possui uma prevalência de $17,1 \%$ entre os dentes inclusos e a sua impactação na posição mesiohorizontal atinge em torno de $10 \%$ desses acometimentos. Além disso, em concordância com o caso aqui descrito, outros estudos, evidenciam que indivíduos do sexo feminino são as mais acometidas pela impactação dentária, com prevalência de $63,2 \%$, possuindo diferença estatística em relação ao sexo masculino $(36,7 \%)^{1,3}$.

A causa mais comum de impactação dos terceiros molares é a discrepância entre maxila e o tamanho do dente, bem como, a falta de espaço na parte inferior do arco². Entretanto, há estudos que indicam os fatores etiológicos da impactação como causa multifatorial, subdividindoo em três grupos: fatores sistêmicos, fatores locais e fatores genéticos ${ }^{3}$. Podemos assim classificar o fator etiológico do presente caso, como fator local do tipo: lesão cística associada à anomalia da posição dentária.

A extração profilática de dentes impactados e não sintomáticos ainda é uma idéia controversa na literatura ${ }^{5}$. Isto se deve ao potencial de complicações do procedimento como trismo, inchaços, fraturas e lesões nervosas. Entretanto, passa a ser indicada a extração, quando na presença dos agravos que frequentemente atingem dentes nessas condições: presença de pericoronarite recorrente; cistos dentários; reabsorção das raízes de dentes adjacentes; infraoclusão; dor; abcessos e cáries não restauráveis ${ }^{3,5}$.

De acordo com Anand, quanto a localização dos dentes impactados, 37\% desses acometem a região de mandíbula e $15 \%$ a região maxilar, apresentando também alguma radiolucência, sugestivo da presença de alguma lesão cística ou tumoral ${ }^{12}$. Segundo Schin, na pesquisa relacionada à prevalência de patologias relacionadas aos terceiros molares mandibulares impactados, $86,4 \%$ dos dentes mandibulares impactados possuíam algum tipo de cisto ou tumor associado ${ }^{5}$. Entre essas lesões, o Cisto dentígero ocupava a primeira posição, com $76,7 \%$ dos acometimentos, com maiores incidências entre $20-29$ anos (28,15\%) e 30-39 anos $(22,22 \%)$.

Portanto, a alta prevalência da associação de dentes impactos com lesões como Odontoma, Cisto Dentígero, Tumor Odontogênico Ceratocístico e Ameloblastoma, tem sido 
encontrados na prática clínica, bem como descritas na literatura². Quando não tratados, essas lesões aumentam a possibilidade de causar fraturas patológicas e deformidades ósseas ${ }^{9}$.

O Cisto Dentígero, radiograficamente, trata-se de uma imagem unilocular radiotransparente de limites bem definidos e com margens escleróticas, em torno da coroa de um dente incluso. De acordo com a classificação estabelecida ${ }^{13}$, o relato de caso aqui evidenciado, se apresenta como um Cisto Dentígero, do tipo central. Esses cistos, quando situado em mandíbula, podem provocar diversos danos ao paciente, como por exemplo, parestesia do nervo alveolar inferior e fraturas patológicas mandibulares ${ }^{2,11}$.

Apesar do tratamento da maioria dos dentes inclusos, associados a lesões como o Cisto Dentígero, serem a exodontia, condutas terapêuticas mais conservadoras, como nos casos de necessidade de aproveitamento desses dentes, podem ser escolhidas pelo profissional. Entre elas, podemos citar a erupção guiada pelo método de tracionamento cirúrgico-ortodôntico, que parece ser a mais eficaz².

Em torno de $85 \%$ dos casos de Cistos Dentígeros, associados a terceiros molares mandibulares, a escolha é pela exodontia desses dentes. Essa conduta é definida, tendo em vista que se trata de um dente sem muita importância para função mastigatória e questões estéticas. Porém, quando tratar-se de lesões de tamanhos maiores, devido aos riscos de injúrias ao nervo alveolar inferior e fragilização do ângulo mandibular, deve-se optar por manobra de descompressão seguida de enucleação ${ }^{11}$.

A realização de exames de rotina, e a consequente descoberta de lesões císticas, associadas a dentes inclusos, é algo comum na prática clínica. Como planejamento para tais casos, o cirurgião dentista deve considerar as possíveis variáveis como: a idade do paciente, localização do cisto e a posição do dente em relação à lesão e outras estruturas anatômicas. $O$ correto manejo e decisão terapêutica facilitarão o sucesso do caso, evitando assim, maiores danos ao paciente ${ }^{2,11}$.

\section{Conclusão}

Devido ao fato de essas lesões poderem alcançar grandes proporções, resultando em assimetria facial, entre outros possíveis danos as estruturas anatômicas do aparelho estomatognático, confirma a necessidade de procedimento cirúrgico e terapêutico imediato. Para este caso, a exodontia do elemento dentário, associado à enucleação da lesão cística, mostrou- 
se uma alternativa viável, segura e eficaz para o tratamento do Cisto Dentígero associado ao terceiro molar inferior incluso e de angulação horizontal.

\section{Referências}

1. Takeshita WM, Utumi JRM. Avaliação quanto à posição e prevalência de dentes impactados nas radiografias panorâmicas da Clínica Odontológica da Faculdade Ingá-PR. J Health Sci Inst. 2012; 30(3):222-226.

2. Ribeiro ET, Bridi MP, Pereira TCR, Velloso TRG, Salim MAA, Bertollo RM, Maia RMLC, Barros LAP, Silva DN. Dentes inclusos associados a cistos e tumores odontogênicos: condutas terapêuticas. Rev. Bras. Pesq. Saúde. 2015; 17(2):78-88.

3. Kaczor-urbanowicz K, Zadurska M, Czochrowska E. Impacted Teeth: An Interdisciplinary Perspective. Adv Clin Exp Med. 2016; 25(3):575-585.

4. Siqueira SP, et al. Estudo de 199 casos de cisto dentígero. SALUSVITA. 2016; 35(4):517-528.

5. Shin, SM, Choi EJ, Moon SY. Prevalence of pathologies related to impacted mandibular third molars. Springerplus. 2016; 5(1):915-919.

6. Bhardwaj B, et al. Mandibular dentigerous cyst in a 10-year-old child. International journal of clinical pediatric dentistry. 2016; 9(3):281-284.

7. Broly E, et al. Cardiac Tamponade Due to Actinomyces odontolyticus Originating From a Dentigerous Cyst. Journal of Oral and Maxillofacial Surgery. 2016; 74(12):2453-2456.

8. Abu-mostafa N, Abbasi A. Marsupialization of a large dentigerous cyst in the mandible with orthodontic extrusion of three impacted teeth. A case report. J Clin Exp Dent. 2017;9(9):11621166.

9. Şahin O. Conservative management of a dentigerous cyst associated with eruption of teeth in a 7-year-old girl: a case report. Journal of the Korean Association of Oral and Maxillofacial Surgeons. 2017; 43(1):1-5.

10.Robinson RA. Diagnosing the most common odontogenic cystic and osseous lesions of the jaws for the practicing pathologist. Modern Pathology.2017; 30(1):96-103.

11. Caliento R, Mannarino FS, Hochuli-vieira E. Cisto dentígero: modalidades de tratamento. Rev Odontol UNESP. 2013; 42(6):458-462.

12. Anand S, Kashyap B, Raj Kumar G, Shruthi BS, Supriya AN. Pericoronal Radiolucencies with Significant Pathology: Clinico-histopathologic Evaluation. Biomed J. 2015; 38(1):148-152.

13. Neville BW, Damm DD, Allen CM, Bouquot JE. Patologia Oral e Maxilofacial. Trad.3a Ed., Rio de Janeiro: Elsevier, 2009, 972p. 